\title{
A field experiment to determine the effect of post-fire salvage on seedbeds and tree regeneration
}

\author{
David F Greene ${ }^{1}$, Sylvie Gauthier ${ }^{2}$, Joseé Noël ${ }^{3}$, Mélanie Rousseau ${ }^{4}$, and Yves Bergeron ${ }^{5}$
}

In North America, Eurasia, and Australia, salvage logging is increasingly being used to mitigate economic losses due to fire, although the effects of this type of intervention are still essentially unknown. In a field experiment in a large recent boreal forest fire in central Quebec, we used 24 paired salvaged and non-salvaged stands to test the effect of salvage on the recruitment of two conifer species possessing an aerial seed bank (Pinus banksiana and Picea mariana). The seedbeds following salvage were, on average, more hospitable to germination, but, incongruously, engendered far lower regeneration densities. The poor recruitment on salvaged sites was due primarily to the loss of seeds following the immediate post-fire salvage, when cone-bearing branches were removed along with the trunks. By contrast, the density of the asexually-recruited Populus tremuloides was relatively unaffected. We suggest simple ways to modify current salvage procedures that would retard this transition from conifer to Populus forest, as well as leaving more wood in situ.

Front Ecol Environ 2006; 4(2): 69-74

$I^{\text {n }}$ n many parts of the world, demand for wood has risen so steeply that almost all of the accessible public forestland has been allocated for production; consequently, governments can no longer forego harvesting burnt forests on land leased to the private sector. This sudden transition to post-fire salvage as a typical response to burning is a global phenomenon (Lindemayer et al. 2004).

Taking Canada as an example, with the exception of certain old growth stands near pre-established logging roads, burnt forests were largely ignored by the logging industry and the provinces. (In Canada, the provinces have jurisdiction over the publicly owned forests.) Within the past 10 years, however, post-fire salvage has become routine near pre-existing roads in Quebec's southern boreal forest and now involves about 25\% of all burns (including remote areas) in the province (Nappi et al. 2004; Figure 1). Recent work (Karr et al. 2004; Lindemayer et al. 2004) in many regions suggests a number of potentially detrimental and long-lasting effects of such practices on ecosystems: (1) changes in the hydrological regime; (2) negative effects of removal

${ }^{1}$ Department of Geography, Concordia University, Montréal, Québec H3G 1M8, Canada; ${ }^{2}$ Natural Resources Canada, Canadian Forest Service, Laurentian Forestry Center, PO Box 3800, Sainte-Foy, Québec G1V 4C7, Canada; ${ }^{3}$ Agence candienne d'evaluation environnementale, Sainte Foy, Quebec G1V 4B8, Canada; ${ }^{4}$ Department of Geography, McGill University, Montréal, Québec H3G 1M8, Canada; ${ }^{5}$ Chaire Industrielle CRSNGUQAT-UQÀM en aménagement forestier durable, Université du Québec en Abitibi-Témiscamingue, Rouyn-Noranda, Québec J9X 5E4, Canada of wood on deadwood-dependent species and on soil characteristics; and (3) diminished capacity of the ecosystem to recover from what amounts to two successive disturbances.

The novelty of widespread salvage means that we know little about its effects. The few studies that have been conducted are very recent and focus on animals. For example, abundance is negatively affected in a few bird and beetle species that rely on standing charred trunks (Hutto 1995; Hoyt and Hannon 2002; Lindemayer et al. 2004; Nappi et al. 2004; Figure 2).

Here we provide the first report of the effects of salvage on seedbeds and tree recruitment, and evaluate the potential changes in species composition. Based on this analysis, we suggest modification of present practices that will reduce their negative impact.

First, however, let us discuss what is currently known about post-fire recruitment in regions prone to standreplacing (ie high intensity) fires. Adapting the germinal argument of Noble and Slatyer (1980), there are four primary ways for plants to recolonize after a stand-replacing burn. The first mechanism for invasion is provided by seed from surviving sources at the nominal burn edge or from the numerous residual stands found in large fires. All species can seed in, but efficacy depends on dispersal capacity relative to the size of the fire (Greene et al. 1999). The second method is regeneration from a buried seedbank; this is commonly seen in fire-prone regions, with the exception of the boreal and mid-latitude cordilleran forests, where it is perhaps precluded by the intensity of the smoldering combustion of the thick organic layer (Keeley and Fotheringham 2000). Third, species can resprout from dormant buds around the root 


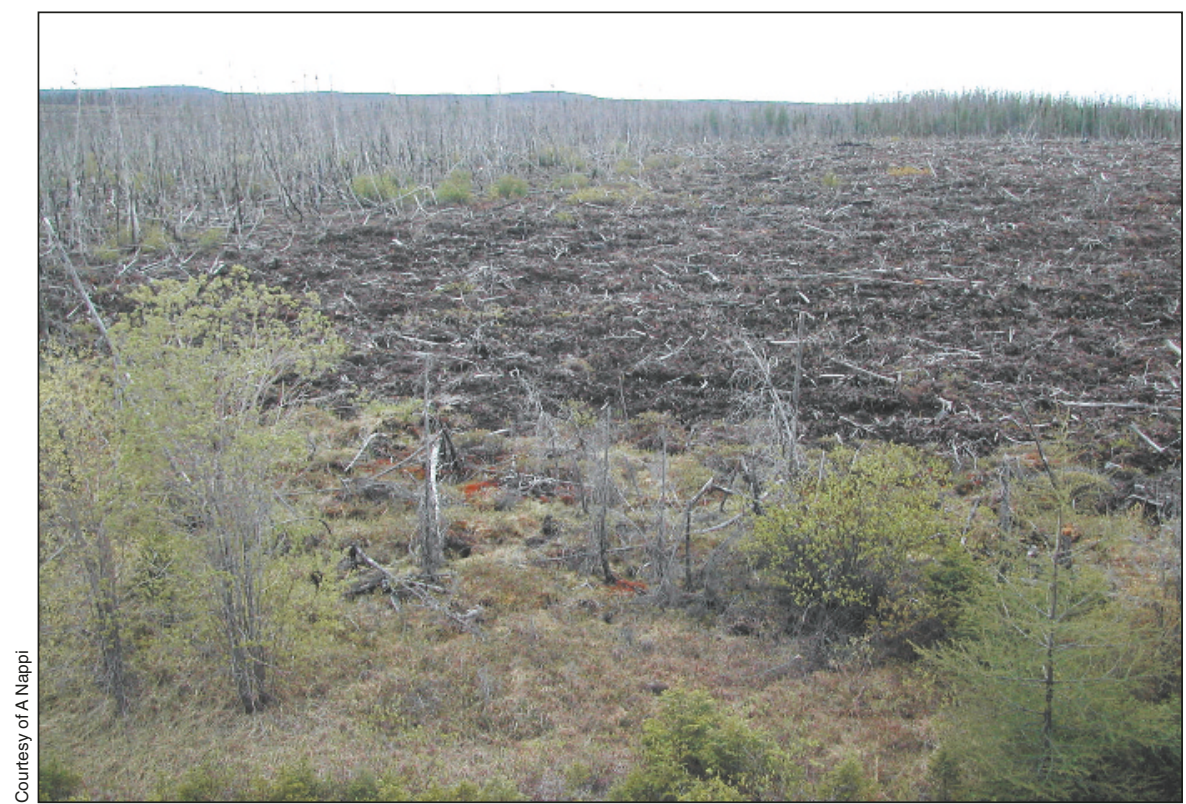

Figure 1. Salvage in the boreal forest in Quebec. From the edge of the burn, one sees in the foreground the stumps and branches from the burnt stems that were cut, the burnt spindly black spruce on boggier ground in the distance (center-left) that were not worth cutting, and off to the upper right unburned black spruce forest.

collar or, more rarely, along the roots. This is quite common among angiosperms (although density and vigor of seedlings vary widely across taxa), and very uncommon among gymnosperms (Enright et al. 1998). The final method is regeneration from an aerial seedbank (serotiny, broadly defined). This is very common in shrubs and trees in the Mediterranean climates of western Australia, Europe, and southern Africa (primarily Proteaceae, Myrtaceae, and Pinaceae) and, in the higher latitudes, in Cupressus, Pinus, and a few other gymnosperm species (Lamont et al. 1991; Greene and Johnson 1999; Tapias et al. 2001). In addition, any species with a matured seed crop not yet opened at the time of the fire, and possessing a sufficiently large fruit, ought to be able to protect a sizeable fraction of the seeds from the very brief passage of the flaming front. For example, in the seasonal tropics of Mexico and Central America, the majority of wind-dispersed seeds mature during the long dry season, the time when fires may occur.

Turning now to North America, the four most common tree species of the fire-prone North American boreal and western cordilleran forests are equipped with traits that are well adapted to immediate recruitment from within a large fire. Three conifers, Pinus banksiana (jack pine), Pinus contorta (lodgepole pine), and Picea mariana (black spruce), possess aerial seedbanks. The cones on the burnt trees are emptied within a few years (Charron and Greene 2002), with the seeds falling on seedbeds that have been much improved by the thinning of the organic mantle (leaf litter and mosses) due to smoldering combustion. Meanwhile, dormant buds in Populus tremuloides (aspen) temporarily activate their hormones after the fire front has passed, causing asexual stems to grow from the roots for about 2 years, until these new clonal stems re-establish hormonal control
(Greene et al. 1999). These four common species flourish in an area subject to recurrent, stand-replacing fires. Unless the fire interval is much shorter or much longer than those of the past few generations, one would expect little change following fire, as the trees replace themselves at a density proportional to the contribution of each species to the pre-fire species composition. As in so many other regions, fire maintains a floristic inertia (Enright et al. 1998; Greene and Johnson 1999; Keeley and Fotheringham 2000; Greene et al. 2004).

Our questions were: does post-fire salvage greatly affect the seedbeds - so crucial to species with aerial seedbanks - and does it diminish the aerial seed supply (ie does it occur before the seeds have been abscised)? Does it impact the regeneration density of the asexually recruiting species? In short, we wished to determine whether current salvage techniques greatly modify the tendency to inertia that would normally rule these systems. Here, we suggest ameliorative practices that would reduce these negative impacts.

\section{Methods}

The 1997 Val Paradis fire occurred in northwest Quebec $\left(49^{\circ} 10^{\prime} \mathrm{N}, 79^{\circ} 17^{\prime} \mathrm{W}\right)$, lasted from June 9 to 11 , and burned 12540 ha with intensities as high as $8000 \mathrm{~kW} \mathrm{~m}^{-2}$. It was extinguished by rain (Hely 2000). Following a cold spring, parts of the burn (especially in the lowlands) still had interstitial ice in the mineral and organic horizons, so that deep removal of organic layers via smoldering combustion was relatively rare. Within the burn, about $95 \%$ of the canopy trees were aspen, black spruce, and jack pine.

Immediately after the fire, in 1997, an agreement was reached with two forestry companies to cordon off 36 oneha stands and keep them protected from salvage. The non-salvaged sites were selected so that there were equal numbers of light, moderate, and severe burning, and three classes of pre-fire tree species composition (aspen-dominated, conifer-dominated, and mixed). Due to concerns about potential infestation by the insect Monochamus scutellatus (the whitespotted sawyer), salvage outside these stands began within 2 months of the fire, resulted in a total harvest of approximately $64 \%$ of the burnt area, and was completed by the end of 1997. The harvesting machines, with extensible, hydraulically-controlled blades able to reach about $5 \mathrm{~m}$ to either side, moved on parallel skidpaths about $6 \mathrm{~m}$ wide. The skidpaths covered about $30 \%$ of the logged area, the other $70 \%$ being the interleaved non-skidpath areas, where the forest floor was 
unaffected by the operation. (Seen from the air these harvested sites look like corduroy fabric.) In the summer of 1999, we also selected one stand in the salvaged areas adjacent to each of the 24 non-salvaged stands, and in what follows we limit the analysis to these 24 pairs of stands. In the middle of each non-salvaged 1-ha stand, a $20 \times 20 \mathrm{~m}$ plot (4\% of one ha) was used for sampling. Within this $400 \mathrm{~m}^{2}$ plot we measured diameter at $1.3 \mathrm{~m}$ height for every burnt stem, ignoring trees that had clearly died prior to the burn. For the salvaged stands, we simply chose (from a distance) a spot to serve as the center of a 20 x $20 \mathrm{~m}$ plot.

Because we had to measure tree diameter at stump height in the salvaged stands, we used the burnt trees in the non-salvaged plots to develop an allometric equation for each species, relating diameter at stump height to the more conventional forestry measure of diameter at breast height. All diameter measures used here for the salvaged stands incorporate this translation from stump height to breast height.

At each $20 \times 20 \mathrm{~m}$ plot we sampled seedbeds using a $30 \mathrm{~m}$ long $(1 \mathrm{~m}$ wide) transect centered within the plot. At the edge of each $1-\mathrm{m}^{2}$ segment of a $30-\mathrm{m}$ transect we observed the seedbed for a total of 31 samples per stand. For the stands salvaged in the late summer of 1999 we estimated the ages of the regenerating stems using terminal budscale scars. By contrast, for the non-salvaged stands we used a set of permanent plots. The data from the nonsalvaged plots indicated essentially no recruitment after 1999 for pine or after 2000 for spruce (Greene et al. 2004); in what follows we will compare demography for the salvaged and non-salvaged sites only for the years 1997, 1998, and 1999.

\section{Results and discussion}

Earlier results (Greene et al. 2004) using experimental sowing of spruce and pine seeds in the non-salvaged sites had shown no surprises; as with the bulk of the forestry literature, the optimal seedbeds for either conifer species were exposed mineral soil, very thin charred organics, or surviving Sphagnum (a moss invariably restricted to spruce-dominated, boggy sites; Greene et al. 1999). The least hospitable seedbeds were thick $(>3 \mathrm{~cm})$ charred moss or leaf litter and charred wood. A result not provided in

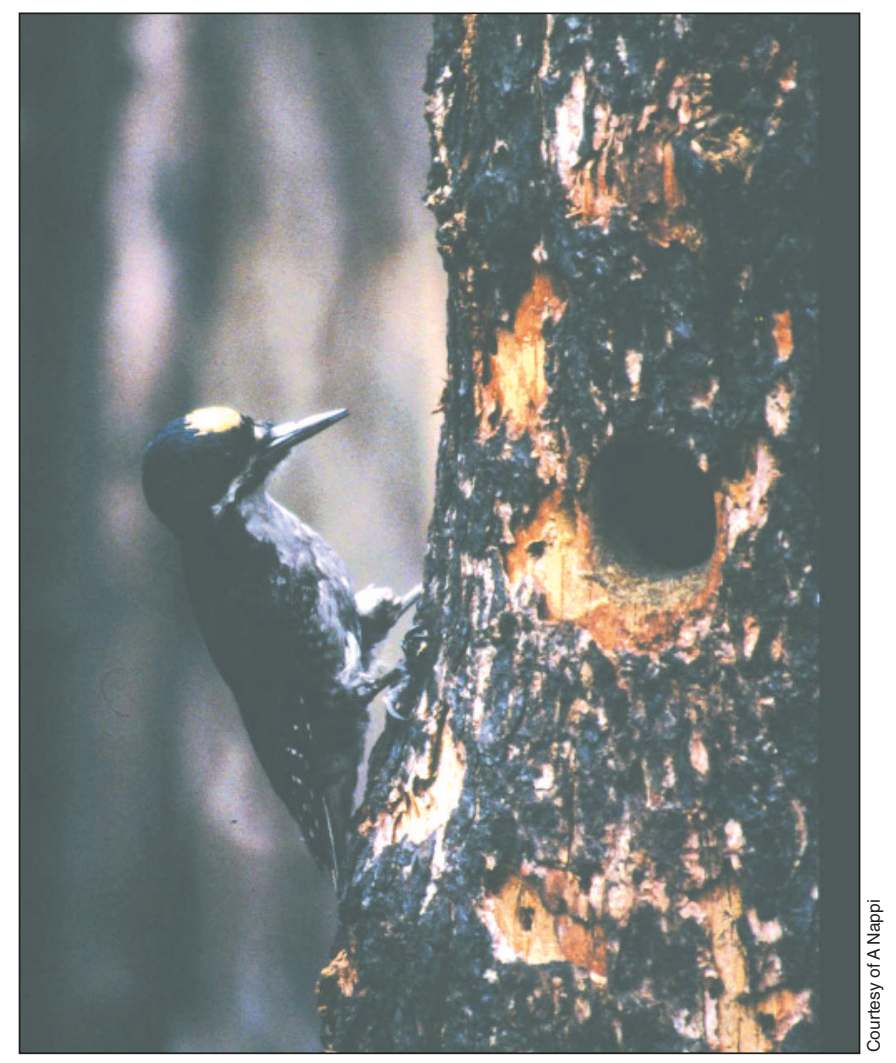

Figure 2. Some woodpecker species rely on wood-boring beetle that colonize burnt trunks.

Greene et al. (2004) concerned a simultaneous sowing on skidpaths: pine and spruce had, respectively, 17 individuals or $5 \%$ higher survivorship on the skidpaths than on the mineral soil in the non-salvaged stands; skidpaths were therefore the best seedbeds anywhere in the burn.

While exposed mineral soil dominated the skidpaths, thick charred organics were the most common seedbed off of the skidpaths located within the salvaged area (Table 1). Nonetheless, because of the presence of skidpaths, mineral soil was, overall, about five times more common on salvaged than on non-salvaged sites. Meanwhile, wood was about six times more common as a substrate on the non-salvaged sites. Surviving Sphagnum was found only in the non-salvaged site. This latter result is not surprising, since the salvaged sites were undoubtedly much drier due to decreased shading and increased evaporation at the surface. In short, despite having no surviving Sphagnum,

Table 1. Proportional cover of seedbed types, based on 24 stands each for the salvage and non-salvage sites

\begin{tabular}{lccccccc}
\hline & $\begin{array}{c}\text { Mineral soil } \\
\text { organics }<2 \mathrm{~cm} \\
\text { thick): } n \text { no } \\
\text { Polytrichum }\end{array}$ & $\begin{array}{c}\text { Mineral soil } \\
\text { (organics }<2 \mathrm{~cm} \\
\text { thick) with cover } \\
\text { of Polytrichum }\end{array}$ & $\begin{array}{c}\text { Surviving } \\
\text { Sphagnum }\end{array}$ & $\begin{array}{c}\text { Thinner } \\
\text { burnt } \\
\text { organics } \\
(>2 ; \leq 10 \mathrm{~cm})\end{array}$ & $\begin{array}{c}\text { Thicker } \\
\text { burnt } \\
\text { organics } \\
(>10 \mathrm{~cm})\end{array}$ & $\begin{array}{c}\text { Surface } \\
\text { wood }\end{array}$ & $\begin{array}{c}\text { Surface } \\
\text { rocks }\end{array}$ \\
\hline Salvage & 0.18 & 0.01 & 0.00 & 0.13 & 0.66 & 0.02 & 0.01 \\
Non-salvage & 0.01 & 0.04 & 0.06 & 0.29 & 0.50 & 0.10 & 0.00
\end{tabular}

For the two mosses: Polytrichum colonized via spores, whereas the Sphagnum recorded here survived the fire after light surface charring. Between the salvage and non-salvage areas, all seedbed proportions were significantly different (difference-of-proportions test; $p<0.00 \mathrm{I}$ ) except for the category "surface rocks" ( $p>0.05$ ). 
the salvaged areas offer, on average, better seedbeds than do the non-salvaged areas, because there is much more exposed mineral soil and far less surface wood.

Despite the higher quality of the salvaged sites, they had much lower densities of conifer seedlings than did the non-salvaged sites (Table 2): four times less for spruce and five times less for pine. The non-dimensional quantity, basal area per area (ie the sum of the cross-sectional areas of all the trees per area studied), is our best single predictor of pre-fire conifer seed density or dormant subsurface bud density among aspen (Greene and Johnson 1999). Here, this predictor accounted for 25 to $41 \%$ of the variance in recruit densities and provided significant correlations in all cases; interestingly, the slopes of the regressions were four to five times smaller for the salvaged sites than for the non-salvaged sites. Note that the magnitude of the slope of each regression is a measure of the strength of the floristic inertia. Furthermore, although we do not show it in Table 2, the correlations improved for both pine and spruce if we used as a predictor the product of basal area per area multiplied by the proportion of optimal seedbeds (the sum of the cover proportions for mineral soil and Sphagnum from Table 1).

Why were the skidpaths not sponsoring denser recruitment for spruce and pine? We suggest three reasons why the salvaged areas promoted poor conifer regeneration: (1) loss of many of the first cohort (germinants) due to the salvage operations; (2) removal of much of the aerial seedbank during the harvest; and (3) drier seedbeds in the more open conditions due to removal of the burnt boles. The first explanation is that the initial cohort within the areas that would become skidpaths was greatly reduced by the movement of the machinery as the trunks were extracted. Using permanent plots in the non-salvaged areas, Greene et al (2004) showed that the largest cohorts for the conifers occurred in 1997 and 1998 (ie the first two summers), with essentially no recruitment after

Table 2. Linear regression results for recruit (seedling or sucker) density $\left(\# \mathrm{~m}^{-2}\right)$ as a function of the dimensionless basal area per area

\begin{tabular}{|c|c|c|c|}
\hline Composition & & Slope & $r^{2}$ \\
\hline Aspen (sv) & 1309 & $(1063-1557)$ & 0.68 \\
\hline Aspen (nsv) & 1102 & $(806-1399)$ & 0.50 \\
\hline Pine (sv) & 757 & $(460-1053)$ & 0.41 \\
\hline Pine (nsv) & 3786 & $(2203-5369)$ & 0.39 \\
\hline Spruce (sv) & 86 & $(54-119)$ & 0.39 \\
\hline Spruce (nsv) & 342 & $(22 I-465)$ & 0.24 \\
\hline \multicolumn{4}{|c|}{$\begin{array}{l}\text { As initial regressions showed that the intercept was never significantly different } \\
\text { from } 0 \text {, here we recast the regressions with the intercept set equal to } 0 \text {. The slope } \\
\text { of the line is proportional to the efficiency with which basal area per area is trans- } \\
\text { lated into recruits per area and is therefore a measure of floristic inertia. Salvage } \\
\text { and non-salvage are indicated by (sv) and (nsv), respectively. The explained variance } \\
\text { from the linear regression is denoted by } r^{2} \text {; the sample size is } 24 \text { in each case. For } \\
\text { spruce and pine, the slopes were significantly different for salvage vs non-salvage } \\
\text { (t-test; } p<0.01) \text {, but not for aspen }(p>0.05 \text { ). }\end{array}$} \\
\hline
\end{tabular}

Panel 1. Overview of the effect of post-fire salvage on tree regeneration in the boreal forest

- Following stand-replacing wildfire in fire-prone regions, the most common competitors, at least among the tree species, are those that rely on aerial seedbanks as opposed to those that reliably resprout. In the system discussed here (the North American boreal forest), aspen (recruiting asexually), black spruce (serotinous), and jack pine (also serotinous) typically regenerate to more or less the same proportions as were found among the canopy trees just before the fire (ie they exhibit the strong inertia of species well-adapted to short fire intervals).

- Immediate post-fire salvage actually improves the seedbeds for the sexually-recruited conifer species dependent on very thin residual organic layers.

- Nonetheless, the density of the serotinous species (but not the asexually-regenerating species) is greatly diminished by salvage. This is mainly because so many of the seed-bearing branches have been removed from the site; thus there are no seeds to fall on the skidpaths and replace the germinants killed by the machinery. Furthermore, in between the skidpaths, fewer seeds are available. Thus, salvage is pushing the system towards dominance by a sprouting species (aspen). This is the same result that has followed clearcutting of unburned forests in Canada and the northern US during the past 100 years.

- There are simple procedures that companies could adopt to increase the density of the serotinous regeneration and thus more faithfully replicate what wildfire achieved prior to the advent of salvage.

- There is no reason to think these ameliorative procedures represent a net cost increase. Indeed, given that the post-salvage natural regeneration is typically quite poor, the suggested ameliorations would reduce total costs because planting is so expensive (averaging US\$700 ha ${ }^{-1}$ ).

2000 - an effect due simply to emptying of the cones. The present analysis of the demography in the salvaged stands shows that there were far too few 1997-origin spruce and pine on the skidpaths. At first glance, an expected ratio of the seedling density on skidpaths to the seedling density on non-skidpaths, would be about 0.3 because skidpaths comprise $30 \%$ of the ground area. However, the expected value would be even higher than that because, as shown above, the skidpaths have much more exposed mineral soil than the intervening non-skidpaths. Nonetheless, for the 1997 cohort of regenerating stems the ratios were 0.05 (spruce) or 0.12 (pine). In 1998 and 1999, the situation was reversed, with ratios of about 2.0 (ie much bigger cohorts on the skidpaths than elsewhere). In short, the first cohort was potentially a large fraction of the total recruitment in an unsalvaged burn, but it was greatly reduced by immediate (first-year) salvage.

So far, we have explained why the better seedbeds in salvaged sites did not enhance the recruit densities: the advantage in seedbed quality was nullified by subsequent mortality due to machinery traffic. However, the density in the salvaged sites is actually far less than in non-salvaged sites, and this is due to the loss of seeds during the operation. A large fraction of the seeds were still in the cones as the harvesters cut and removed the trunks; the slash piles (ie the areas where the pruned branches are 


\section{Panel 2. Seedbeds, seed size, and fire}

- Globally, boreal tree species have small seeds (around $0.5 \mathrm{mg}$ for aspen and up to $7 \mathrm{mg}$ for fir). Allometrically, small seeds lead to small germinants, with germinant length roughly proportional to seed mass raised to the power 0.33 (consider the relationship between the radius of a sphere to its volume...) Thus, boreal tree species have germinant lengths ranging only from $0.5-3 \mathrm{~cm}$

- In intact forests, thick organic layers composed of leaf litter or moss averaging about $5-15 \mathrm{~cm}$ in depth are quite common. But small germinants cannot penetrate such thicknesses. Thus, if the seed germinates on top of the organic layer, the developing root of the freely-transpiring geminant will never reach the underlying water-rich mineral soil before it desiccates. If the seed is under the organic layer (eg under the autumnal leaf fall), it cannot push up through the leaves (and thus escape the darkness) before its maternal carbohydrate reserves have been exhausted.

- Thin organic layers (a few $\mathrm{cm}$ thick or less) are never found in intact forest unless a mammal has been digging for roots or the wind has uprooted a tree from wet soil. Small-seeded species in intact forests can germinate only on fallen logs (because their elevated position means that deposited leaves are quickly re-entrained by the wind) - and only on the most rotted portions of the logs. These rotted portions average only about $1-5 \%$ of the intact forest floor.

- By contrast, smoldering combustion (the slow, glowing oxidation that one sees in the interior of a campfire and that can continue well after the flames have been extinguished) leads to a forest floor that has, on average, $40 \%$ coverage for the very thin (a few cm or less in thickness) organic layers that are optimal for small-seeded species.

- Thus, for small-seeded species, intense fires normally represent a wealth of recruitment opportunities.

piled) on the roadsides had many cone-bearing branches. Another large fraction of the cones fell to the ground when subsequent surface heating on sunny days opened the scales, permitting a few seeds to slip out. However, seeds derived from fallen cones are never as well-dispersed as seeds released from elevated positions. Worse, especially for black spruce, the cones lay as a crowded mass attached to the discarded upper tops of trees; anecdotally, we once counted over 700 spruce seeds lying clustered under a $2-\mathrm{m}$ long cone-bearing upper trunk, but found not a single germinant in this dark, damp environment.

A final explanation for the low conifer recruitment densities in the salvage area seems to us the least important: seedbeds in salvaged sites will be somewhat drier due to near-surface evaporation from the soil. A salvaged stand ought to have much more light at the soil surface than a non-salvaged, burnt stand (which permits only about 35\% light transmission). One example which proves this enhanced drying effect has already been mentioned, namely the absence of surviving Sphagnum in the low-lying salvage areas (Table 1). Corroborating evidence is also found in the paucity of Polytrichum (a moss species that colonizes the wettest exposed mineral soil via spores) on upland salvaged sites (Table 1). Nonetheless, the observed survivorship on the skidpaths was as good as for our sowing on mineral soil seedbeds in the non-salvaged stands, and so the extra desiccation cannot be too serious a challenge for these germinants.

Meanwhile, for aspen, skidpaths sponsored roughly the $30 \%$ of suckers (asexual recruits derived from meristems on shallow thin roots) we might expect for 1997. Given that there was no serious loss of dormant buds along the roots during the harvesting operation, it is not surprising that the slopes of the relationship between basal area/area and sucker density were not significantly different for salvage versus non-salvage sites (Table 2 ).

In summary, we have shown here for the first time that conventional salvage has a number of important effects on post-fire tree regeneration. First, it improves seedbeds and early survivorship for the small-seeded species: the increase in the amount of exposed mineral soil - with or without a veneer of colonizing Polytrichum - is much greater than the loss of the receptive Sphagnum seedbeds. While these post-salvage seedbeds are probably somewhat drier than without harvesting, this seems to have little effect on the germinants, at least in the 3 years following this particular fire. Much more dramatic is the loss of spruce and pine seeds due to the salvage operation. A final consequence is that in the absence of expensive planting (around US\$700 ha-1), we will see a shift at the landscape scale to ever-greater dominance by the unaffected aspen. Thus, the same shift that has occurred in the northern US and southern Canada following clearcutting of conifer-dominated forests (Hearndon et al. 1992; Carleton and MacLellan 1994) will now be seen in burned forests as well. We expect the floristic effects discussed here to be generally true in all fire-prone forests because the main competition is between reliable resprouters and serotinous species (eg Pinus as compared to other genera in the Mediterranean, or serotinous Eucalyptus competing with other species in Australia).

\section{Implications for management}

Simple procedures could ameliorate these effects. First, salvage could be delayed, say, 2 years, by which time almost all of the serotinous seeds would have abscised (Charron and Greene 2002). Arguments against this approach are (1) that there will be substantial damage to early conifer regeneration during summer harvesting (one might estimate about a quarter of the recruitment could be eliminated, with the bulk of the loss on the skidpaths); and (2) the vast majority of the wood will be withdrawn from the system, with negative consequences for many birds, insects, and soil organisms (one of the main arguments against salvage).

A more useful suggestion is not to delay salvage, but rather to leave some fraction of the burnt trees (eg 10\% overall of the conifers across the landscape) to serve as seed sources. These remaining trees - in long lines parallel to the skidpaths - could then augment the recruitment by seed deposition on the nearby (and clement) skidpath surfaces, as well as on the inter-path areas. This latter pro- 
posal serves the dual purpose of enhancing regeneration and maintaining some flux of woody debris within the system. Whether the approach advocated here would engender sufficient shading to permit some survival of Sphagnum (and any other herbaceous plants dependent on high water availability) is not clear. Certainly, one can assume that this prescription would reduce the problems faced by those animal species dependent on standing or downed wood (Lindemayer et al. 2004), although the relationship between the percentage of trees remaining and the ameliorative effects on biodiversity and soils needs to be elucidated in order to guide management decisions.

In summary, our suggested solution should be of general interest for all regions where high-intensity, stand-replacing fires occur, and where there are woody plants of sufficient size to warrant post-fire salvage. In these systems, the fuel loadings are sufficiently great that smoldering combustion renders soil seedbanks an unlikely mechanism for recolonization. Thus, in these very large fires, except near their edges, the developing canopy dynamics are utterly dominated, for many decades, by the relative contributions and growth rates of the stems derived from aerial seedbanks and from dormant buds. Conventional salvage will push the canopy composition towards domination by asexually-recruiting species, while our suggested modification of forestry practices will constrain this tendency. Furthermore, the proposal to leave behind long, wellspaced lines of serotinous trees will minimize the negative effects discussed by Lindenmeyer et al (2004), by reducing the loss of cellulose from the system and providing habitat for animal species dependent on standing or downed logs.

\section{Acknowledgements}

We thank D Charron, M Purdon, S Auger, N Nadeau, R Maltais, M Bédard, A Maletto, M Kehle, and P Sutherland for field assistance. We also thank the companies Norbord and Tembec, as well as the Quebec Department of Natural Resources, Forest Branch, for their collaboration during the research. This work was funded by the Sustainable Forest Management Network, the Natural Sciences and Engineering Research Council of Canada, and the Canadian Forest Service. It constitutes a contribution of the NSERC-UQAT-UQÀM Industrial Chair in Sustainable Forest Management.

\section{References}

Carleton TJ and MacLellan P. 1994. Woody vegetation responses to fire versus clear-cutting logging: a comparative survey in the central Canadian boreal forest. Ecoscience 1: 141-52.

Charron I and Greene DF. 2002. Post-wildfire seedbeds and tree establishment in the southern mixedwood boreal forest. Can J For Res 32: 1607-15.

Enright NJ, Marsula R, Lamont BB, and Wissel C. 1998. The ecological significance of canopy seed storage in fire-prone environments: a model for resprouting shrubs. J Ecol 86: 960-73.

Greene DF and Johnson EA. 1999. Modeling the recruitment of Populus tremuloides, Pinus banksiana, and Picea mariana following fire in the mixedwood boreal forest of central Saskatchewan. Can J For Res 29: 462-73.

Greene DF, Zasada JC, Sirois L, et al. 1999. A review of regeneration dynamics of boreal forest tree species. Can J For Res 29: 824-39.

Greene DF, Noel J, Bergeron Y, et al. 2004. Recruitment of Picea mariana, Pinus banksiana, and Populus tremuloides across a burn severity gradient following wildfire in the southern boreal forest of Quebec. Can J For Res 34:1845-57.

Hearnden KW, Millson SV, and Wilson WC. 1992. A report on the status of forest regeneration. Toronto, Canada: Queen's Printer.

Hély C. 2000. Influence de la végétation et du climat dans le comportement des incendies en forêt boréale mixte canadienne (PhD thesis). Montreal, Canada: Université du Québec à Montréal.

Hoyt JS and Hannon J. 2002. Habitat associations of black-backed and three-toed woodpeckers in the boreal forest of Alberta. Can J For Res 32: 1881-88.

Hutto RL. 1995. The composition of bird communities following stand-replacement fires in northern Rocky Mountain (USA) conifer forests. Conserv Biol 9: 1041-58.

Karr JR, Rhodes JJ, Minshall GW, et al. 2004. The effects of postfire salvage logging on aquatic ecosystems in the American west. BioScience 54: 1029-33.

Keeley JE and Fotheringham C. 2000. Role of fire in regeneration from seed. In: Fenner M (Ed). Seeds: the ecology of regeneration in plant communities. Cambridge, MA: CAB International.

Lamont BB, Maitre DCL, Cowling RM, and Enright NJ. 1991. Canopy and seed storage in woody plants. Bot Rev 57: 277-317.

Lindenmayer DB, Foster DR, Franklin JF, et al. 2004. Salvage harvesting policies after natural disturbances. Science 303: 1303.

Nappi A, Drapeau P, and Savard J-PL. 2004. Salvage logging after wildfire in the boreal forest: is it becoming a hot issue for wildlife? For Chron 80: 67-74.

Noble IR and Slatyer RO. 1980. The use of vital attributes to predict successional changes in plant communities subject to recurrent disturbances. Vegetatio 43: 5-21.

Tapias R, Gil L, Fuentes-Utrilla P, and Pardos JA. 2001. Canopy seed banks in Mediterranean pines of south-eastern Spain: a comparison between Pinus halepensis Mill, $P$ pinaster Ait, $P$ nigra Arn and P pinea L. J Ecol 89: 629-38. 